\title{
ANALISA KEBUTUHAN INDUSTRI BAGI ALUMNI JURUSAN AKUNTANSI PERGURUAN TINGGI
}

\author{
ANALYSIS OF INDUSTRIAL NEEDS \\ FOR ALUMNI ACCOUNTING DEPARTMENTS OF HIGHER EDUCATION
}

\author{
Ikhwani Ratna ${ }^{1}$, Nanda Suryadi', \\ Univesitas Islam Negeri Sulthan Syarif Kasim Riau ${ }^{1,2}$ \\ nanda.suryadi@uin-suska.ac.id ${ }^{2}$
}

\begin{abstract}
Tracer Study is also useful in providing important information about the relationship between tertiary institutions and the professional work world, assessing the relevance of tertiary education, information for stakeholders, and completeness of requirements for tertiary accreditation. This study had two orientations, namely: (a) as a tracer study as the information from alumni would be used as input to improve the learning process and increase the relevance of graduate competencies to the job market needs; $(b)$ as an application of a descriptive research approach in which the results of data tracking information from alumni were analyzed and described in tables and diagrams. This study resulted in interesting findings. First, accounting department of Universitas Islam Negeri Suska was a favorite major in accordance with the primary choice of the alumni when studying in college. Second, most of the alumni wanted to work in government, but in reality, most of them worked as private employees. Third, most of the alumni worked in accordance with the field studied and the majors taken during education. Fourth, alumni had the ability which is not less competitive compared to alumni from other tertiary institutions. Fifth, increased time of practical work in companies/government agencies was given to able to improve the experience needed in the job market. Sixth, there were several competencies that need to be improved, namely teaching and learning process, which include English language skills, computer skills and specific practice majors.
\end{abstract}

Keywords : Tracer Study, Accounting Alumni

ABSTRAK
Tracer Study juga bermanfaat dalam menyediakan informasi penting mengenai
hubungan antara perguruan tinggi dan dunia kerja professional, menilai relevansi
pendidikan tinggi, informasi bagi pemangku kepentingan (stakeholders), dan
kelengkapan persyaratan bagi akreditasi perguruan tinggi. Penelitian ini memiliki dua
orientasi: (a) sebagai penelitian tracer study karena informasi dari alumni akan
digunakan sebagai masukan memperbaiki proses pembelajaran dan peningkatan
relevansi kompetensi lulusan dengan kebutuhan dunia kerja; (b) sebagai penerapan
pendekatan penelitian deskriptif dimana dalam penelitian ini data hasil pelacakan
informasi dari alumni dianalisis dan dideskripsikan ke dalam tabel dan diagram.
Penelitian ini menghasilkan penemuan yang menarik diantaranya pertama Jurusan
akuntansi UIN Suska merupakan jurusan favorit yang sesuai dengan pilihan utama para
alumni ketika menempuh pendidikan di perguruan tinggi. Kedua Sebagian besar alumni


berkeinginan bekerja dibidang pemerintahan , namun pada kenyataannya sebagian besar bekerja sebagai karyawan swasta. Ketiga Sebagian besar alumni bekerja sesuai dengan bidang yang dipelajari dan jurusan yang ditempuh selama pendidikan. Keempat Alumni memiliki kemampuan yang tidak kalah dibandingkan dengan alumni dari perguruan tinggi lain. Ke lima Untuk dapat meningkatkan pengalaman yang dibutuhkan di dunia kerja maka dapat diberikan dengan menambah waktu praktek kerja lapangan di perusahaan/instansi pemerintah. Ke Enam Terdapat beberapa kompetensi yang perlu ditingkatkan proses belajar mengajarnya di kampus diantaranya adalah kemampuan bahasa inggris, kemampuan computer dan praktek spesifik jurusan.

Kata Kunci: Tracer Study, Alumni Akuntansi

\section{PENDAHULUAN}

Jurusan akuntansi adalah salah satu darijurusan favorit di Universitas Islam Negeri Sultan Syarif Kasim Riau (UIN SUSKA Riau). Hal ini bisa dilihat dari besarnya minat dari alumni SMA/SMK untuk mendaftar ke jurusan ini dari tahun ke tahun. Jika dilihat dari alasan besarnya minat para alumni SMA/SMK tersebut terhadap jurusan akuntansi ini antara lain adalah karena banyaknya tersedia lapangan pekerjaan yang membutuhkan lulusan akuntansi dalam menjalankan roda organisasinya. Untuk memenuhi kebutuhan lapangan pekerjaan di bidang akuntansi, Jurusan Akuntansi UIN Suska telah membuka konsentrasi jurusan di bidang akuntasi manajemen, akuntansi pemerintahan dan akuntansi keuangan. Namun dibalik semua kompetensi yang diajarkan di Jurusan Akuntansi UIN Suska, tidak semua alumni yang dapat mengambil manfaat dari besarnya peluang lapangan kerja tersebut.

Jurusan Akuntansi UIN Suska diharapkan dapat menjawab permasalahan dalam hal persaingan kerja alumninya didunia kerja. Diantaranya adalah dengan meningkatkan kualitas pembelajarannya dan juga kesesuaian kompetensi yang diajarkan dengan kebutuhan pasar. Dengan demikian, maka jurusan akuntansi membutuhkan data yang akurat dari lapangan untuk menjadi bahan masukan dalam menjawab permasalahan yang dihadapi terkait kompetensi alumninya.

Salah satu metode yang dapat digunakan untuk membantu perguruan tinggi dalam perbaikan sistem dan pengelolaan pendidikan adalah dengan melaksanakan Tracer Study (Ramadiani, 2016). Tracer Study merupakan salah satu studi yang mampu menyediakan informasi yang bermanfaat bagi kepentingan evaluasi perguruan tinggi dan selanjutnya dapat digunakan untuk penyempurnaan dan penjaminan kualitas lembaga pendidikan tinggi. Tracer Study dapat mengukur dan melacak kinerja dan saran-saran lulusan maupun pengguna lulusan sehingga dapat diperoleh indikator yang jelas tentang jumlah, profil kerja masa mendatang, serta kompetensi yang diperlukan oleh dunia kerja.

Dengan demikian Jurusan Akuntansi dapat mempersiapkan kurikulum dan sistem pendidikannya agar lulusan yang dihasilkan dapat beradaptasi dengan dunia kerja. Hal ini mengindikasikan arti penting informasi dari alumni dan pengguna alumni, sebagai bahan pertimbangan untuk penyusunan standar kompetensi. Pada giliran berikutnya, standar kompetensi tersebut digunakan oleh jurusan sebagai bahan pertimbangan dalam program pengembangan, khususnya penyusunan 
kurikulum dan materi pembelajaran (Hamzah et al., 2018).

Tracer Study juga bermanfaat dalam menyediakan informasi penting mengenai hubungan antara perguruan tinggi dan dunia kerja professional, menilai relevansi pendidikan tinggi, informasi bagi pemangku kepentingan (stakeholders), dan kelengkapan persyaratan bagi akreditasi perguruan tinggi. Dalam pelaksanaannya, Tracer Study semestinya dilaksanakan oleh lembaga yang menjembatani antara perguruan tinggi dengan dunia usaha dan industri. Tracer Study perlu dilakukan secara melembaga, terstruktur dan dengan metodologi dan analisis yang tepat untuk memperoleh hasil yang terukur, akurat dan dapat diperbandingkan (Sintia \& Fitriani, 2017).

Tujuan utama kegiatan tracer study adalah mengidentifikasikan kinerja lulusan, serta menghimpun saran-saran baik dari alumni maupun pengguna alumni. Berbekal hasil penelitian ini dapat digunakan untuk membenahi program pembelajaran agar mampu membangun kompetensi mahasiswa sesuai dengan kompetensi yang diperlukan oleh dunia kerja. Selanjutnya, dengan kompetensi yang memadai, maka diharapkan dapat meningkatkan daya saing lulusan (Bachtiar \& Lathif, 2017).

Dalam kegiatan ini yang menjadi sasaran adalah alumni Jurusan Akuntansi yang meliputi alumni yang bekerja pada instansi pemerintah, swasta maupun wirausaha. Masalah yang melatarbelakangi pentingnya dilakukan penelitian ini adalah bahwa masa tunggu alumni untuk mendapatkan pekerjaan sesuai kualifikasi pendidikannya masih cukup lama. Hal ini diindikasikan oleh adanya beberapa orang alumni yang menyatakan belum mendapatkan pekerjaan yang mapan.

Berdasarkan pengamatan di lapangan, menunjukkan adanya masalah kesenjangan antara kompetensi yang diajarkan di jurusan dengan tuntutan pasar kerja. Hal ini disebabkan, karena perkembangan dan perubahan kompetensi yang cepat sesuai perkembangan di era global. Dengan demikian, jurusan ini seharusnya senantiasa memantau kompetensi terkini yang dituntut oleh dunia kerja.

Penelitian terdahulu oleh Suharti \& Laksono (2015) dan Harianto et al., (2019) menunjukkan bahwa salah satu faktor yang menyebabkan lamanya masa tunggu lulusan untuk memperoleh kesempatan kerja, antara lain karena kompetensi lulusan belum sesuai dengan kebutuhan user (dunia kerja). Jika kondisi ini dibiarkan terus berlangsung, maka harapan untuk menghasilkan lulusan yang mempunyai kompetensi bekerja di pemerintahan maupun swasta tidak akan berhasil seperti yang diharapkan. Artinya bahwa proses pembelajaran yang dilaksanakan juga harus dibenahi kembali dengan mempertimbangkan saran dari alumni dan pengguna, sehingga kompetensi yang diajarkan akan sesuai dengan kompetensi yang diperlukan pasar kerja.

Dalam rangka mendukung usaha UIN Suska Riau agar lulusannya mempunyai life skill yang memadai untuk menghadapi tantangan masa depan, maka kualitas pembelajaran harus ditingkatkan. Untuk meningkatkan kualitas pembelajaran tersebut, mutlak disertai dengan perbaikan kurikulum. Dalam hal ini tracer study merupakan sebuah studi pelacakan jejak alumni yang sangat strategis menghimpun informasi guna perbaikan kualitas pembelajaran, sinkronisasi kurikulum, dan layanan pendidikan pada umumnya. 
Tracer Study atau yang sering disebut sebagai survey alumni atau survey "follow up" adalah studi mengenai lulusan lembaga penyelenggara pendidikan tinggi. Studi ini mampu menyediakan berbagai informasi yang bermanfaat bagi kepentingan evaluasi hasil pendidikan tinggi dan selanjutnya dapat digunakan untuk penyempurnaan dan penjaminan kualitas lembaga pendidikan tinggi yang bersangkutan (Harianto et al., 2019). Tracer Study juga bermanfaat dalam menyediakan informasi penting mengenai hubungan antara pendidikan tinggi dan dunia kerja professional, menilai relevansi pendidikan tinggi, informasi bagi pemangku kepentingan (stakeholders), dan kelengkapan persyaratan bagi akreditasi pendidikan tinggi.

Perguruan tinggi perlu melaksanakan Tracer Study karena membutuhkan umpan balik dari alumni dalam usahanya untuk perbaikan sistem dan pengelolaan pendidikan. Perguruan tinggi di awal tahun ajaran menentukan arah kebijakan pendidikan tinggi dari masukkan berupa kondisi, pengalaman, dan motivasi. mahasiswa baru yang masuk ke perguruan tinggi tersebut (Rahmi, 2015). Masukkan mengenai kondisi, pengalaman dan motivasi ini menentukan pula perguruan tinggi dalam menerapkan sistem dan pengelolaan pendidikan dalam hal pola/proses pengajaran dan pembelajaran, penelitian, praktikum, workshop, laboratorium, studio ataupun riset. Penerapan sistem pengajaran dan pembelajaran inipun akan dipengaruhi pula oleh kebijakan pendidikan yang ditetapkan oleh perguruan tinggi. Hasil dari masukkan berupa kondisi, pengalaman dan motivasi mahasiswa, sistem dan kebijakan pendidikan di perguruan tinggi, dan proses pengajaran dan pembelajaran di perguruan tinggi akan membantu dalam membentuk karakter/kompetensi dari lulusan perguruan tinggi itu sendiri (Hamzah et al., 2018).

Lulusan/alumni dari perguruan tinggi umumnya akan memiliki pengetahuan, kemampuan, motivasi dan kompetensi yang dibutuhkan untuk memasuki dunia kerja Hasil dari pendidikan tinggi adalah pengetahuan, kemampuan dan kompetensi alumni perguruan tinggi yang dibutuhkan untuk memasuki dunia kerja. Hasil-hasil ini beserta kondisi saat alumni menjalani pekerjaan di awal karir mereka merupakan hal-hal yang dibutuhkan bagi perguruan tinggi untuk perbaikan sistem dan pengelolaan pendidikan. Kebutuhan untuk mengetahui rekam jejak alumni serta hubungan pendidikan tinggi dengan pekerjaan inilah yang menjadi konsep dasar dalam penelitian Tracer Study. Pelaksanaan Tracer Study idealnya dilakukan kepada alumni perguruan tinggi pada 1-3 tahun semenjak kelulusan. Kondisi ini dianggap ideal karena 1-3 tahun setelah kelulusan alumni dianggap sudah memiliki pengalaman dan kompetensi dalam pekerjaan serta pengetahuan akan dunia kerja (terekspos di dunia kerja). Pengalaman dan kompetensi di dunia kerja inilah yang kemudian akan menjadi umpan balik alumni bagi perguruan tinggi terkait hubungan pendidikan tinggi dengan pekerjaan

\section{METODEPENELITIAN}

Penelitian ini memfokuskan pada usaha melacak informasi dari alumni dan selanjutnya mendiskripsikan hasil pelacakan tersebut secara sistematis. Penelitian ini memiliki dua orientasi: (a) sebagai penelitian tracer study karena informasi dari alumni akan digunakan sebagai masukan memperbaiki proses pembelajaran dan peningkatan relevansi kompetensi 
lulusan dengan kebutuhan dunia kerja; (b) sebagai penerapan pendekatan penelitian deskriptif dimana dalam penelitian ini data hasil pelacakan informasi dari alumni dianalisis dan dideskripsikan ke dalam tabel dan diagram.

Populasi adalah suatu kelompok dari elemen penelitian, (unit terkecil) yang merupakan sumber dari data yang diperlukan dalam analisa. Adapun populasi dari penelitian ini adalah seluruh alumni jurusan akuntansi UIN Suska sampai dengan bulan juli 2018 yang berjumlah 1876 orang alumni.

Penelitian ini menggunakan batas kesalahan $10 \%$ untuk sampel penelitian, diambil dengan menggunakan rumus slovin dengan rumus sebagai berikut :

$$
\begin{array}{lll} 
& \mathrm{n}=\frac{N}{\left(N . d^{2}\right)+1} \\
& \mathrm{n}=\frac{1876}{\left(1876 \times 10 \% \%^{2}\right)+1} \\
& \mathrm{n}=95 \text { orang } \\
\text { dimana } & \text { : Jumlah sample } \\
\mathrm{n} \quad & \text { : Jumlah populasi } \\
\mathrm{d} \quad \text { : Persen kesalahan yang ditolerir }
\end{array}
$$

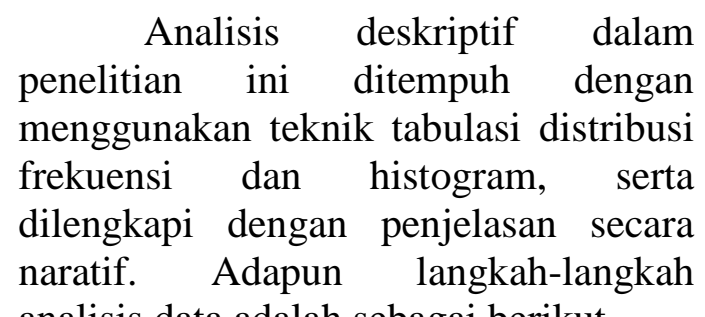
analisis data adalah sebagai berikut.

1. Instrumen yang telah terisi oleh responden diperiksa kelengkapannya.Instrumen yang tidak lengkap dianggap tidak memenuhi syarat untuk dianalisis.

2. Dibuat buku kode sebagai upaya untuk memandu peneliti mengkonversi data kualitatif menjadi kuantitaif (numerik).
3. Menyusun Data view dan Variable view sebagai aturan main sistem data numerik dari semua variabel.

4. Melakukan input data, dari instrumen ke tabel induk data penelitian.

5. Analisis data secara deskriptif

6. Membuat tabel distribusi frekuensi, histogram, dan penjelasan seperlunya

\section{HASIL DAN PEMBAHASAN Pendidikan Alumni}

Sebagian besar alumni menganggap bahwa jurusan akuntansi merupakan jurusan favorit yang menjadi pilihan utama mereka pada saat hendak menempuh pendidikan di perguruan tinggi dengan prosentasi sebesar $61 \%$ menjadi pilihan I. Namun pada saat menempuh pendidikan perguruan tinggi, para alumni lebih memilih untuk tidak aktif di kegiatan organisasi mahasiswa dengan persentase $77 \%$, karena lebih mementingkan kegiatan belajar dikampus. Hal ini tentu berdampak kepada kemampuan beradaptasi alumni dalam menghadapi dunia kerja, dimana dalam dunia kerja terdapat beberapa kompetensi yang dibutuhkan seperti kerjasama tim, kepemimpinan yang mana kompetensi tersebut dapat diperoleh melalui kegiatan di organisasi mahasiswa.

\section{Pekerjaan Alumni}

Berdasarkan hasil survey terhadap jenis pekerjaan yang dimintai oleh alumni, sebagian besar responden menjawab bahwa pekerjaan yang diminati adalah PNS dan pegawai BUMN dengan persentase $70 \%$. Hal ini dikarenakan bidang pekerjaan tersebut memiliki jaminan terhadap penghasilan yang tetap dan jaminan hari tua. Namun kondisi ini tidak sesuai dengan bidang 
pekerjaan alumni dimana sebagian besar alumni bekerja sebagai karyawan swasta dan hanya sedikit alumni jurusan akuntansi yang bekerja sebagai PNS.

Berdasarkan hasil survey diatas, dapat dilihat bahwa sebagian besar alumni jurusan akuntansi lebih berminat terhadap mencari pekerjaan dibandingkan dengan membuka usaha baru atau membuka lapangan pekerjaan. Menjadi pekerja/karyawan maka akan dibatasi dengan penghasilan yang tetap dan relatif terbatas setiap bulannya. Padahal untuk dapat berhasil dan memperoleh penghasilan yang besar akan lebih mudah diperoleh dengan membuka lapangan pekerjaan baru dibandingkan menjadi karyawan. Oleh karena itu, perlu dibentuk mental jiwa usaha bagi mahasiswa jurusan akuntansi dengan memberikan bekal kompetensi dan motivasi dari dosen yang memberikan pelajaran di kampus agar dapat mengubah pola pikir menjadi pengusaha dibandingkan dengan pekerja (Harianto et al., 2019).

\section{Kesesuaian Pendidikan dengan Pekerjaan}

Berdasarkan data yang diperoleh dari kuesioner dari responden, dapat diperoleh hasil bahwa sebagian besar responden mempunyai bidang pekerjaan yang sesuai dengan pendidikan atau jurusan yang ditempuh sebesar $67 \%$. Hal ini dapat menjadi indikasi bahwa jurusan akuntansi masih menjadi jurusan yang dibutuhkan oleh lapangan pekerjaan. Hal ini sesuai dengan perolehan hasil penelitian Mustikawati et al., (2016) yang sama-sama meneliti tracer study jurusan akuntansi.

\section{Pengalaman yang dibutuhkan oleh alumni dari kampus.}

Berdasarkan hasil tanggapan responden terhadap pengalaman yang dibutuhkan oleh alumni, diperoleh hasil bahwa pengalaman belajar dikampus menjadi pengalaman yang paling penting dengan nilai interval 3.6, sedangkan pengalaman ketika magang di perusahaan atau instasi juga penting dalam meningkatkan kompetensi alumni dalam menghadapi dunia kerja dengan nilai interval 3.6. Mengingat pentingnya pengalaman tersebut maka diharapkan kepada dosen dapat mengefektifkan setiap pertemuan di kelas dengan proses belajar mengajar yang dapat berguna bagi mahasiswa di dunia kerja nantinya. Disamping itu, jurusan dapat mempertahankan kebijakan praktek kerja lapangan di perusahanaan dan juga menambah durasi waktu pada saat praktek kerja lapangan minimal selama satu semester (6 bulan).

\section{Kemampuan bersaing}

Berdasarkan hasil kuesioner di atas diperoleh hasil bahwa alumni jurusan akuntansi memiliki kompetensi yang tidak kalah dibandingkan dengan alumni jurusan akuntansi dari jurusan akuntansi universitas lain dengan persentase $80 \%$ merasa mampu. Hal ini dapat menjadi gambaran bahwa jurusan akuntansi telah mencetak alumni yang memiliki kemampuan dan daya saing dalam dunia kera. Untuk itu perlu dipertahankan kemampuan dan kompetensi alumni agar tetap dapat bersaing dalam menghadapi dunia kerja nantinya (Bakhtiar, 2017).

\section{Kontribusi jurusan dan kompetensi yang dibutuhkan}

Berdasarkan hasil kuesioner di atas diperoleh hasil bahwa alumni jurusan akuntansi memiliki kompetensi yang tidak kalah dibandingkan dengan alumni jurusan akuntansi dari jurusan akuntansi universitas lain dengan persentase $80 \%$ merasa mampu. Hal ini dapat menjadi gambaran bahwa jurusan 
akuntansi telah mencetak alumni yang memiliki kemampuan dan daya saing dalam dunia kera. Untuk itu perlu dipertahankan kemampuan dan kompetensi alumni agar tetap dapat bersaing dalam menghadapi dunia kerja nantinya. Hal ini sesuai dengan hasil penelitian yang dilakukan oleh Rahmi (2015) dimana pengembangan sistem tracer study yang dilakukan mampu berpartisipasi dalam mengukur kemampuan mahasiswa jurusan dan diperolah hasil yang baik.

\section{PENUTUP}

\section{Kesimpulan}

Berdasarkan tracer study yang telah dilakukan kepada alumni jurusan Akuntansi di UIN Suska Provinsi Riau, maka dapat disimpulkan beberapa hal sebagai berikut :

1. Jurusan akuntansi UIN Suska merupakan jurusan favorit yang sesuai dengan pilihan utama para alumni ketika menempuh pendidikan di perguruan tinggi.

2. Sebagian besar alumni berkeinginan bekerja dibidang pemerintahan, namun pada kenyataannya sebagian besar bekerja sebagai karyawan swasta.

3. Sebagian besar alumni bekerja sesuai dengan bidang yang dipelajari dan jurusan yang ditempuh selama pendidikan.

4. Alumni memiliki kemampuan yang tidak kalah dibandingkan dengan alumni dari perguruan tinggi lain.

5. Untuk dapat meningkatkan pengalaman yang dibutuhkan di dunia kerja maka dapat diberikan dengan menambah waktu praktek kerja lapangan di perusahaan/instansi pemerintah.

6. Terdapat beberapa kompetensi yang perlu ditingkatkan proses belajar mengajarnya di kampus diantaranya adalah kemampuan bahasa inggris, kemampuan computer dan praktek spesifik jurusan.

\section{Saran}

Dari hasil tracer study ini, dapat dijadikan sebagai bahan perbaikan mengenai hal-hal yang dirasakan kurang oleh para alumni Jurusan Akuntansi di UIN Suska. Selain itu, tracer study dilakukan untuk membantu dalam hal akademik, misalkan untuk akreditasi, perbaikan proses kurikulum, dan lainlain. Untuk keakuratan data dan membuat database alumni yang lebih baik, sebaiknya tracer studi dilakukan dengan cara online dengan menggunakan media website uin suska dan juga media social dan menyasar semua alumni yang ada. Sebaiknya Jurusan Akuntansi UIN Suska mempererat hubungan dengan para alumni, agar terjalin komunikasi yang baik, selain itu UIN Suska akan lebih mudah mengetahui keberadaan para alumni, dan alumni mengetahui kondisi UIN Suska, dan juga untuk dapat membantu meningkatkan akses informasi lowongan kerja bagi alumni yang baru lulus.

Tracer study sebaiknya dilaksanakan secara berkelanjutan, agar lebih mudah untuk mengetahui keberadaan alumni dengan lengkap. Selain itu, rasa enggan untuk mengisi kuesioner dapat diminimalisir dengan cara mengurangi jumlah pertanyaan pada kuesioner tracer study. Namun kuesioner yang dibuat tetap mengacu pada tracer study dikti dan kebutuhan yang diperlukan setiap jurusan. 
DAFTAR PUSTAKA

Bakhtiar, M. I., \& Latif, S. (2017). Tracer study alumni: Upaya pengembangan prodi bimbingan konseling universitas negeri makassar. Jurnal Kajian Bimbingan dan Konseling, 2(1), 32-40.

Hamzah, M., L., Ermina, R., \& Astri, A., P. (2018). Sistem Aplikasi Sarana Prasarana Perguruan Tinggi Menggunakan Teknologi Near Field Communication Berbasis Android. INTECOMS: Journal of Information Technology and Computer Science, 1(2), 251-261.

Harianto, K., Pratiwi, H., \& Suhariyadi, Y. (2019). Sistem Monitoring Lulusan Perguruan Tinggi Dalam Memasuki Dunia Kerja Menggunakan Tracer Study. Media Sahabat Cendekia.

Mustikawati, R. I., Nugroho, M. A., Setyorini, D., Yushita, A. N., \& Timur, R. P. (2016). Analisis Kebutuhan Soft Skill dalam Mendukung Karir Alumni Akuntansi. Jurnal Pendidikan Akuntansi Indonesia, 14(2).

Ramadiani, R. (2016). Tracer Study Menggunakan Framework Bootstrap.

Rahmi, A. N. (2015). Pengembangan Sistem Tracer Study Online Berbasis Website di STMIK AMIKOM Yogyakarta. CSRID (Computer Science Research and Its Development Journal), 6(2), 108-117.

Sintiani, I., \& Fitriani, L. (2017). Pengembangan Aplikasi Tracer Study STT-Garut. Jurnal Algoritma, 14(1), 118-124.
Suharti, L., \& Laksono, F. P. (2015). Studi Penelusuran (Tracer Study) Terhadap Alumni Program Studi Manajemen Fakultas Ekonomika dan Bisnis Universitas Kristen Satya Wacana. PROCEEDING call for Paper Pekan Ilmiah Dosen FEB-UKSW. 